\title{
Volumetric Behavior of Binary Mixtures of Alkoxyethanols and Some Selected Amines at 298.15 K
}

\author{
Ayasen Jermaine Kemeakegha, ${ }^{1}$ Grace Agbizu Cookey, ${ }^{2}$ and Welford-Abbey Lolo Izonfuo ${ }^{1}$ \\ ${ }^{1}$ Department of Chemical Sciences, Niger Delta University, Wilberforce Island, PMB 71, Yenagoa, Bayelsa State, Nigeria \\ ${ }^{2}$ Department of Chemistry, Rivers State University of Science \& Technology, PMB 5080, Port Harcourt, Rivers State, Nigeria
}

Correspondence should be addressed to Welford-Abbey Lolo Izonfuo; welfordabbey@yahoo.com

Received 23 September 2014; Revised 9 January 2015; Accepted 9 January 2015

Academic Editor: Felix Sharipov

Copyright (C) 2015 Ayasen Jermaine Kemeakegha et al. This is an open access article distributed under the Creative Commons Attribution License, which permits unrestricted use, distribution, and reproduction in any medium, provided the original work is properly cited.

\begin{abstract}
Densities of binary mixtures of 2-methoxyethanol (2-MeO-EtOH) and 2-ethoxyethanol (2-EtO-EtOH) with hexylamine (HLA), diethylamine (DEA), triethylamine (TEA), tert-butylamine (TBA), aniline (ANL), and benzylamine (BLA) have been determined at varying compositions of the alkoxyalkanols at $298.15 \mathrm{~K}$. The excess molar volumes, VE, of the binary mixtures were calculated from the experimental density data of the mixtures and the component single solvents. The calculated excess molar volumes were fitted into the Redlich-Kister polynomial to obtain the fitting coefficients and standard deviations. The excess molar volumes of the binary mixtures of all the solvent systems investigated were negative over the entire range of the solvents composition. The negative values were attributed to stronger hydrogen bond formations between the unlike molecules of mixtures than those between the like molecules of the pure components. The magnitude of the excess molar volumes of the binary mixtures of 2-methoxyethanol and the aliphatic amines were in the order TBA $>$ TEA $>$ DEA $>$ HEA. For the two aromatic amines, the magnitudes were in the order BLA $>$ ANL. For binary mixtures of the amines and 2-ethoxyethanol, the magnitudes were in the order DEA $>$ TEA $>$ TBA $>$ HEA at compositions where the mole fraction of 2-EtO-EtOH was $\leq 0.5$ and TBA $>$ TEA $>$ DEA $>$ HEA above 0.5 mole fraction of 2-EtO-EtOH.
\end{abstract}

\section{Introduction}

Studies of excess thermodynamic functions are useful tools in understanding the nature of molecular interactions in binary liquid mixtures [1]. In chemical industry, knowledge of the properties of binary liquid mixtures is essential in designs involving chemical separations, heat transfer, mass transfer, and fluid flow [2-7]. The mixing of two solvents has been reported to result in specific interactions such as hydrogen bonding, dipole-dipole, and charge transfer reactions [5]. Strong and weak interactions between unlike molecules in mixtures lead to deviations from ideality. Deviations from ideality in binary liquid mixtures are usually associated with synergism and are attributed to differences in the chemistry and molecular architecture of the mixing solvents [8-14] as well as the experimental conditions such as temperature and the mixing ratios of the binary liquids.

Alcohols and amines are known for their self-association through intermolecular hydrogen bonding. Amines are very important in various applications. For example, diethylamine is used as a corrosion inhibitor in the production of resins, dyes, rubbers, and pharmaceuticals. tert-Butylamine is an intermediate in the preparation of pesticides, pharmaceuticals, dyes, and other organic compounds [15]. Alcohols are very important solvents in a number of industrial processes and have several applications as reagents or solvents, hand sanitizers, antifreeze, and antiseptics as well as preservatives in science and industry [6]. Some alcohols are bifunctional in nature. Bifunctional alcohols, like alkoxypropanols, have demonstrated excellent cleaning properties as a result of their dual molecular architecture [6]. In general, bifunctional alcohols, like alkoxyethanols, are hydroxyethers which are widely used for various analytical and industrial purposes [16-21].

A survey of the literature reveals several studies on the excess properties of binary organic solvent mixtures including amines and bifunctional alcohols [22-31]. For example, $\mathrm{Pal}$ and Kumar have reported the excess molar volumes and viscosity deviations of binary liquid mixtures of [2(2-butoxyethoxy) ethanol] and [2-(2-ethoxyethoxy) ethanol] 
with 1-propanol at different temperatures [15]. Viscosities of binary liquid mixtures of 2-(2-methoxyethoxy) ethanol, 2(2-ethoxyethoxy) ethanol, and 2-(2-butoxyethoxy) ethanol with methyl, ethyl, and propylacetates at various temperatures have also been reported by the same authors [16]. A number of workers have also reported their findings on studies conducted on mixtures of several other bifunctional systems [15-34]. For example, Holgado et al. [35] have reported the excess molar volumes and viscosity deviations of binary mixtures of 2-methoxyethanol and 2-butanone at different temperatures. The literature is however scanty on studies regarding binary mixtures of 2-alkoxyethanols with the named amines. This study is therefore aimed at providing mixing data in terms of the excess molar volumes of binary mixtures of 2-alkoxyethanols with tert-butylamine, hexylamine, diethylamine, triethylamine, aniline, and benzylamine. 2-Methoxyethanol and 2-ethoxyethanol were used as the alkoxyethanols to see the effect of the chain length of the alkoxy group on the excess molar volumes of the binary solvent systems. The excess molar volume data obtained from the measured densities of the binary mixtures at $298.15 \mathrm{~K}$ over the entire range of solvents composition have been used to interpret the types and strengths of intermolecular interactions in the binary mixtures of the solvent systems investigated. Our findings on the volumetric behavior of these binary mixtures are reported hereunder.

\section{Experimental}

2.1. Materials. Hexylamine, diethylamine, and triethylamine of analytical grade were products of Merck, Germany. 2Methoxyethanol (96\%) was a product of Kanto Chemicals, Japan. 2-Ethoxyethanol (95\% pure) and benzylamine (99\% pure) were from BDH Chemicals, England, UK. tertButylamine (98\% pure) was from Riedel-De Haenag SeelzeHannover and aniline (99\% pure) was from May and Baker, England. All the solvents were dried using molecular sieves and the pure solvents were recovered via distillation.

2.2. Measurements. Binary mixtures of the pure solvents were prepared by weight. The exact volumes of the cosolvents were calculated from their densities at $298.15 \mathrm{~K}$ and mixed. The compositions of the binary mixtures ranged from 0.0004 to 0.9998 mole fraction of the 2-alkoxyethanols. All weighings were done using a Sartorius Analytical Balance with a precision of $\pm 10^{-4}$. The densities of the pure solvents and binary mixtures were determined with a $10 \mathrm{~mL}$ capacity single stem capillary pyknometer at the working temperature of $(298.15 \pm 0.01) \mathrm{K}$. The pyknometer was calibrated with doubly distilled water at atmospheric pressure and at the working temperature. The accuracy of the density measurements was estimated to be $\pm 1 \times 10^{-5} \mathrm{~g} \mathrm{~cm}^{-3}$. The calculated densities of the pure solvents at $298.15 \mathrm{~K}$ are shown in Table 1 and are comparable to values obtained in the literature [36-38].

\section{Results and Discussion}

The excess molar volumes, $V^{E}$, of the binary mixtures were calculated from the measured density data using

$$
V^{E}=V-\left[X_{1} V_{1}+X_{2} V_{2}\right] \text {. }
$$

TABLE 1: Densities, $\rho\left(\mathrm{g} / \mathrm{cm}^{3}\right)$, of pure solvents at $298.15 \mathrm{~K}$.

\begin{tabular}{lccc}
\hline Solvent & Acronym & Experimental & Literature \\
\hline Aniline & ANL & 1.0165 & 1.0175 \\
Benzylamine & BLA & 0.9896 & 0.9943 \\
Hexylamine & HLA & 0.7611 & $0.7620^{\mathrm{a}}$ \\
& & & $0.7016^{\mathrm{a}}$, \\
Diethylamine & DEA & 0.7017 & $0.6926^{\mathrm{b}}$ \\
& & & $0.7230^{\mathrm{a}}$, \\
Triethylamine & TEA & 0.7201 & $0.7235^{\mathrm{b}}$ \\
tert-Butylamine & TBA & 0.6893 & 0.6908 \\
2-Methoxyethanol & 2-MeO-EtOH & 0.9604 & $0.96028^{\mathrm{a}}$, \\
& & & $0.96024^{\mathrm{b}}$ \\
2-Ethoxyethanol & 2-EtO-EtOH & 0.9256 & $0.92520^{\mathrm{a}}$, \\
& & & $0.92515^{\mathrm{c}}$ \\
\hline
\end{tabular}

${ }^{\mathrm{a}}$ References [23], ${ }^{\mathrm{b}}[21]$, and ${ }^{\mathrm{c}}[22]$.

In (1), $X_{1}$ and $X_{2}$ are the mole fractions of the alkoxyethanols and amines, respectively. $V, V_{1}$, and $V_{2}$ are the respective molar volumes of the binary mixtures and the single component solvents. $V$ was obtained from

$$
V=\frac{M}{\rho} .
$$

In (2), $\rho$ is the density of the mixture, calculated from the experimental density data, and $M$ is the molar mass of the mixture calculated from (3) where $M_{1}$ and $M_{2}$ are the molar masses of the pure components

$$
M=X_{1} M_{1}+X_{2} M_{2} .
$$

The densities and calculated excess molar volumes of the binary mixtures at the various mole fractions of $2-\mathrm{MeO}$ $\mathrm{EtOH}$ and 2-EtO-EtOH are listed in Tables 2 and 3 and shown in Figures 1 and 2, respectively.

The values of the calculated excess molar volumes, $V^{E}$, of the binary mixtures were fitted into the Redlich-Kister polynomial (4) and the fitting coefficients, $A_{i}$, were evaluated by the method of least squares

$$
V^{E}=X(1-X) \sum_{i=0}^{n} A_{i}(2 X-1)^{i} .
$$

In (4), $n$ is the number of fitting coefficients and the other parameters are as defined earlier.

With the values of $n$, and the total number of experimental data points, $m$, the standard deviations, $\sigma$, of the excess molar volumes, $\sigma\left(V^{E}\right)$, were calculated using (5)

$$
\sigma\left(V^{E}\right)=\sqrt{\frac{\sum\left(V_{\mathrm{expt}}^{E}-V_{\mathrm{cal}}^{E}\right)^{2}}{m-n}} .
$$

The values of the fitting coefficients and the standard deviations of the excess molar volumes of the various mixtures of 2$\mathrm{MeO}-\mathrm{EtOH}+$ amines and 2-EtO-EtOH + amines are shown in Tables 4 and 5, respectively. 
TABLE 2: Densities, $\rho\left(\mathrm{g} / \mathrm{cm}^{3}\right)$, and excess molar volumes, $V^{E}\left(\mathrm{~cm}^{3} / \mathrm{mol}\right)$, of binary mixtures of 2-MeO-EtOH with named amines at $298.15 \mathrm{~K}$.

\begin{tabular}{|c|c|c|c|c|c|c|}
\hline \multirow{2}{*}{$X_{1}(2 \mathrm{MeOEtOH})$} & \multicolumn{2}{|c|}{ Aniline } & \multicolumn{2}{|c|}{ Benzylamine } & \multicolumn{2}{|c|}{ Hexylamine } \\
\hline & $\rho\left(\mathrm{g} / \mathrm{cm}^{3}\right)$ & $V^{E}\left(\mathrm{~cm}^{3} / \mathrm{mol}\right)$ & $\rho\left(\mathrm{g} / \mathrm{cm}^{3}\right)$ & $V^{E}\left(\mathrm{~cm}^{3} / \mathrm{mol}\right)$ & $\rho\left(\mathrm{g} / \mathrm{cm}^{3}\right)$ & $V^{E}\left(\mathrm{~cm}^{3} / \mathrm{mol}\right)$ \\
\hline 0.0004 & 1.0165 & -0.0012 & 0.9896 & -0.0014 & 0.7611 & -0.0003 \\
\hline 0.1004 & 1.0168 & -0.0784 & 0.9888 & -0.0502 & 0.7624 & -0.1984 \\
\hline 0.1988 & 1.0175 & -0.1313 & 0.9893 & -0.1039 & 0.7638 & -0.3763 \\
\hline 0.3008 & 1.0178 & -0.1608 & 0.9898 & -0.1508 & 0.7649 & -0.4951 \\
\hline 0.3958 & 1.0180 & -0.1698 & 0.9903 & -0.1926 & 0.7656 & -0.5643 \\
\hline 0.4978 & 1.0179 & -0.1623 & 0.9906 & -0.2194 & 0.7659 & -0.5861 \\
\hline 0.5996 & 1.0177 & -0.1426 & 0.9908 & -0.2274 & 0.7658 & -0.5515 \\
\hline 0.6981 & 1.0173 & -0.1080 & 0.9907 & -0.2113 & 0.7653 & -0.4795 \\
\hline 0.7999 & 1.0168 & -0.0702 & 0.9903 & -0.1697 & 0.7642 & -0.3573 \\
\hline 0.8984 & 1.0164 & -0.0326 & 0.9895 & -0.0993 & 0.8268 & -0.1917 \\
\hline 0.9998 & 0.9604 & -0.0004 & 0.9604 & -0.0013 & 0.9604 & -0.0006 \\
\hline \multirow{2}{*}{$X_{1}(2 \mathrm{MeOEtOH})$} & \multicolumn{2}{|c|}{ Diethylamine } & \multicolumn{2}{|c|}{ Triethylamine } & \multicolumn{2}{|c|}{ tert-Butylamine } \\
\hline & $\rho\left(\mathrm{g} / \mathrm{cm}^{3}\right)$ & $V^{E}\left(\mathrm{~cm}^{3} / \mathrm{mol}\right)$ & $\rho\left(\mathrm{g} / \mathrm{cm}^{3}\right)$ & $V^{E}\left(\mathrm{~cm}^{3} / \mathrm{mol}\right)$ & $\rho\left(\mathrm{g} / \mathrm{cm}^{3}\right)$ & $V^{E}\left(\mathrm{~cm}^{3} / \mathrm{mol}\right)$ \\
\hline 0.0004 & 0.7017 & -0.0003 & 0.7201 & -0.0002 & 0.6893 & -0.0011 \\
\hline 0.1004 & 0.7081 & -0.7095 & 0.7175 & -0.7589 & 0.6957 & -0.7821 \\
\hline 0.1988 & 0.7141 & -1.3252 & 0.7226 & -1.4113 & 0.7018 & -1.4231 \\
\hline 0.3008 & 0.7181 & -1.7439 & 0.7259 & -1.8053 & 0.7062 & -1.8850 \\
\hline 0.3958 & 0.7206 & -2.0023 & 0.7284 & -2.0517 & 0.7096 & -2.2375 \\
\hline 0.4978 & 0.7212 & -2.0637 & 0.7293 & -2.1012 & 0.7105 & -2.3393 \\
\hline 0.5996 & 0.7199 & -1.9409 & 0.7286 & -1.9656 & 0.7101 & -2.2959 \\
\hline 0.6981 & 0.7174 & -1.6825 & 0.7267 & -1.6945 & 0.7073 & -2.0221 \\
\hline 0.7999 & 0.7132 & -1.2518 & 0.7228 & -1.2143 & 0.7025 & -1.5249 \\
\hline 0.8984 & 0.8078 & -0.6855 & 0.8183 & -0.6855 & 0.7957 & -0.8113 \\
\hline 0.9998 & 0.9604 & -0.0005 & 0.9604 & -0.0005 & 0.9604 & -0.0015 \\
\hline
\end{tabular}

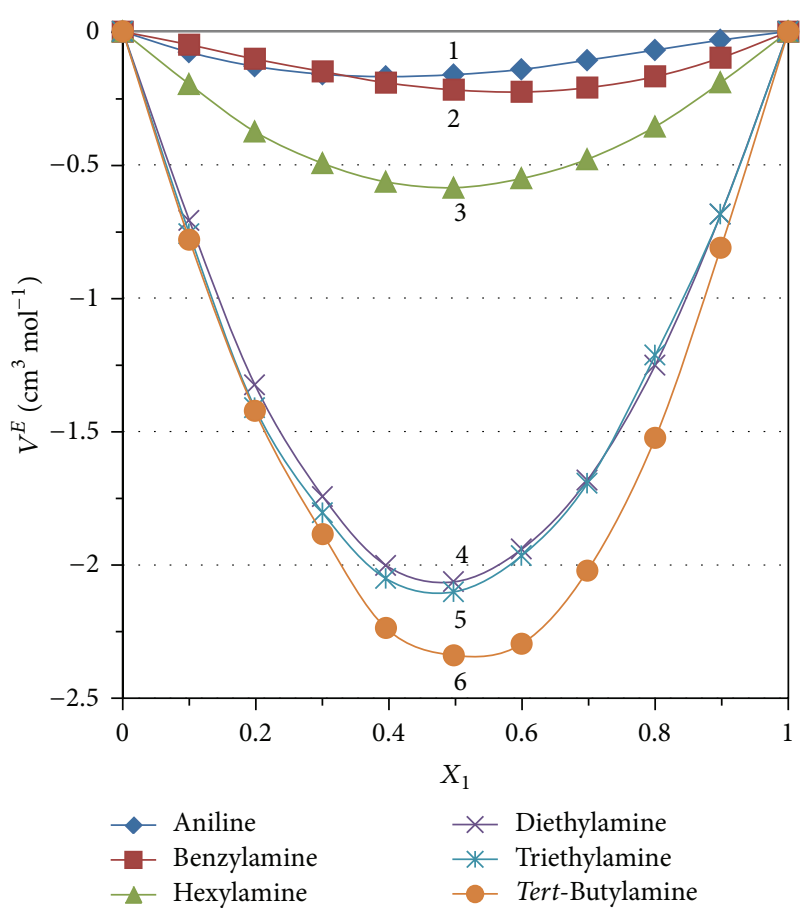

FIGURE 1: Plots of excess molar volumes $\left(V^{E}\right)$ versus mole fraction of 2-MeO-EtOH at $298.15 \mathrm{~K}$ for the binary mixtures of 2-MeO-EtOH with ANL (1), BLA (2), HEA (3), DEA (4), TEA (5), and TBA (6).

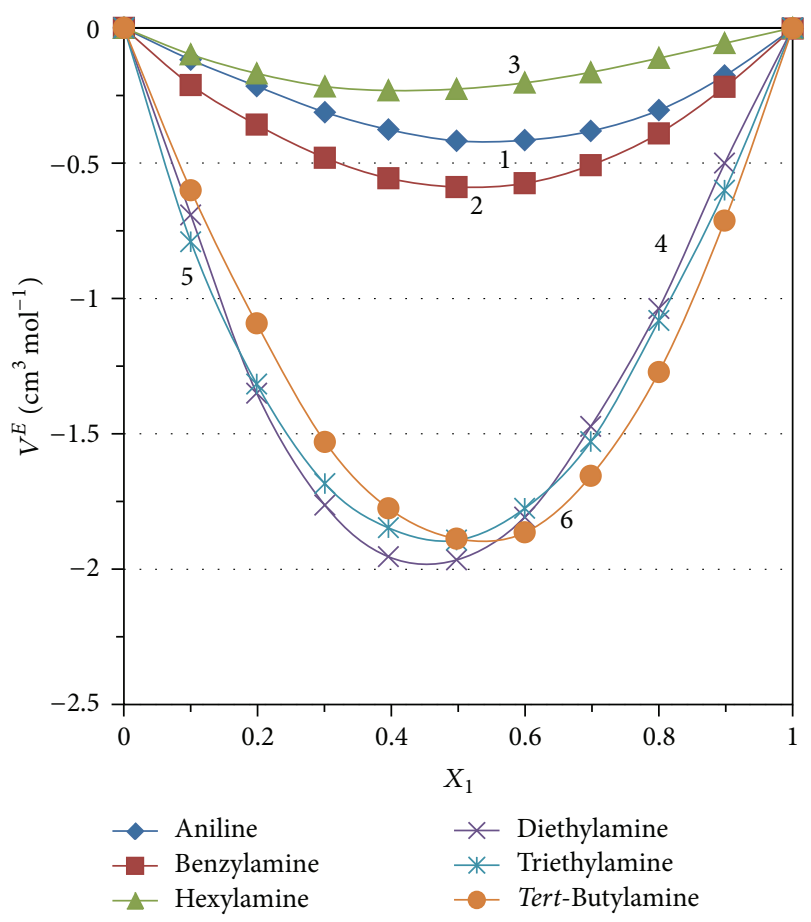

Figure 2: Plots of excess molar volumes $\left(V^{E}\right)$ versus mole fraction of 2-EtO-EtOH at $298.15 \mathrm{~K}$ for the binary mixtures of 2-EtO-EtOH with ANL (1), BLA (2), HEA (3), DEA (4), TEA (5), and TBA (6). 
TABLE 3: Densities, $\rho\left(\mathrm{g} / \mathrm{cm}^{3}\right)$, and excess molar volumes, $V^{E}\left(\mathrm{~cm}^{3} / \mathrm{mol}\right)$, of binary mixtures of 2-EtO-EtOH with named amines at $298.15 \mathrm{~K}$.

\begin{tabular}{|c|c|c|c|c|c|c|}
\hline \multirow{2}{*}{$X_{1}(2 \mathrm{EtOEtOH})$} & \multicolumn{2}{|c|}{ Aniline } & \multicolumn{2}{|c|}{ Benzylamine } & \multicolumn{2}{|c|}{ Hexylamine } \\
\hline & $\rho\left(\mathrm{g} / \mathrm{cm}^{3}\right)$ & $V^{E}\left(\mathrm{~cm}^{3} / \mathrm{mol}\right)$ & $\rho\left(\mathrm{g} / \mathrm{cm}^{3}\right)$ & $V^{E}\left(\mathrm{~cm}^{3} / \mathrm{mol}\right)$ & $\rho\left(\mathrm{g} / \mathrm{cm}^{3}\right)$ & $V^{E}\left(\mathrm{~cm}^{3} / \mathrm{mol}\right)$ \\
\hline 0.0004 & 1.0165 & -0.0011 & 0.9896 & -0.0012 & 0.7611 & -0.0001 \\
\hline 0.1004 & 1.0177 & -0.1181 & 0.9904 & -0.2114 & 0.7617 & -0.0986 \\
\hline 0.1988 & 1.0188 & -0.2159 & 0.9919 & -0.3582 & 0.7623 & -0.1684 \\
\hline 0.3008 & 1.0199 & -0.3118 & 0.9931 & -0.4801 & 0.7626 & -0.2167 \\
\hline 0.3958 & 1.0206 & -0.3759 & 0.9940 & -0.5558 & 0.7628 & -0.2315 \\
\hline 0.4978 & 1.0211 & -0.4177 & 0.9944 & -0.5882 & 0.7628 & -0.2261 \\
\hline 0.5996 & 1.0211 & -0.4153 & 0.9946 & -0.5747 & 0.7626 & -0.2032 \\
\hline 0.6981 & 1.0207 & -0.3816 & 0.9938 & -0.5075 & 0.7623 & -0.1643 \\
\hline 0.7999 & 1.0199 & -0.3044 & 0.9926 & -0.3901 & 0.7619 & -0.1120 \\
\hline 0.8984 & 1.0184 & -0.1765 & 0.9908 & -0.2189 & 0.7614 & -0.0569 \\
\hline 0.9998 & 0.9256 & -0.0033 & 0.9256 & -0.0035 & 0.9256 & -0.0001 \\
\hline \multirow{2}{*}{$X_{1}(2 \mathrm{EtOEtOH})$} & \multicolumn{2}{|c|}{ Diethylamine } & \multicolumn{2}{|c|}{ Triethylamine } & \multicolumn{2}{|c|}{ tert-Butylamine } \\
\hline & $\rho\left(\mathrm{g} / \mathrm{cm}^{3}\right)$ & $V^{E}\left(\mathrm{~cm}^{3} / \mathrm{mol}\right)$ & $\rho\left(\mathrm{g} / \mathrm{cm}^{3}\right)$ & $V^{E}\left(\mathrm{~cm}^{3} / \mathrm{mol}\right)$ & $\rho\left(\mathrm{g} / \mathrm{cm}^{3}\right)$ & $V^{E}\left(\mathrm{~cm}^{3} / \mathrm{mol}\right)$ \\
\hline 0.0004 & 0.7017 & -0.0002 & 0.7201 & -0.0001 & 0.6893 & -0.0011 \\
\hline 0.1004 & 0.7079 & -0.6923 & 0.7257 & -0.7905 & 0.6938 & -0.6005 \\
\hline 0.1988 & 0.7139 & -1.3502 & 0.7297 & -1.3161 & 0.6983 & -1.0928 \\
\hline 0.3008 & 0.7175 & -1.7642 & 0.7326 & -1.6847 & 0.7020 & -1.5299 \\
\hline 0.3958 & 0.7189 & -1.9542 & 0.7340 & -1.8476 & 0.7039 & -1.7751 \\
\hline 0.4978 & 0.7187 & -1.9658 & 0.7345 & -1.8934 & 0.7046 & -1.8876 \\
\hline 0.5996 & 0.7169 & -1.8084 & 0.7337 & -1.7751 & 0.7041 & -1.8649 \\
\hline 0.6981 & 0.7138 & -1.4727 & 0.7319 & -1.5293 & 0.7019 & -1.6562 \\
\hline 0.7999 & 0.7099 & -1.0370 & 0.7285 & -1.0812 & 0.7785 & -1.2719 \\
\hline 0.8984 & 0.8055 & -0.4997 & 0.8247 & -0.6005 & 0.7938 & -0.7121 \\
\hline 0.9998 & 0.9256 & -0.0001 & 0.9256 & -0.0003 & 0.9256 & -0.0025 \\
\hline
\end{tabular}

TABLE 4: Fitting coefficients and standard deviations of binary mixtures of 2-MeO-EtOH and amines at 298.15 K.

\begin{tabular}{lccccr}
\hline Binary mixtures & $A_{0}$ & $A_{1}$ & $A_{2}$ & $A_{3}$ & $A_{4}$ \\
\hline Hexylamine $\left(V^{E} / \mathrm{cm}^{3} \mathrm{~mol}^{-1}\right)$ & 0.0030 & -2.2587 & 1.6553 & 1.4212 & -0.8207 \\
Diethylamine $\left(V^{E} / \mathrm{cm}^{3} \mathrm{~mol}^{-1}\right)$ & 0.0106 & -8.0379 & 6.1468 & 4.6293 & -2.7503 \\
Triethylamine $\left(V^{E} / \mathrm{cm}^{3} \mathrm{~mol}^{-1}\right)$ & 0.0097 & -8.7262 & 8.1396 & 2.8943 & -2.3202 \\
tert-Butylamine $\left(V^{E} / \mathrm{cm}^{3} \mathrm{~mol}^{-1}\right)$ & -0.0034 & -8.0987 & 3.8583 & 7.3791 & -3.1182 \\
Aniline $\left(V^{E} / \mathrm{cm}^{3} \mathrm{~mol}^{-1}\right)$ & 0.0012 & -0.9225 & 1.3586 & -0.2374 & -0.1992 \\
Benzylamine $\left(V^{E} / \mathrm{cm}^{3} \mathrm{~mol}^{-1}\right)$ & 0.0012 & -0.4698 & -0.4922 & 1.2316 & -0.2687 \\
\hline
\end{tabular}

\section{Excess Molar Volumes, $V^{E}$, of Binary Mixtures of 2-Alkoxyethanols and the Named Amines}

The excess molar volumes, $V^{E}$, of the binary mixtures investigated in the study were all negative over the entire range of solvents composition at $298.15 \mathrm{~K}$. These are shown in Tables 2 and 3 and Figures 1 and 2. Plots of the excess molar volumes as a function of mole fraction of the alkoxyethanols in the binary mixtures show minima in the mole fraction range of $0.45-0.55$ of the alkoxyethanols. In the binary mixtures of 2-methoxyethanol and the named amines, the minimum occurs at $\sim 0.50$ for DEA and TEA; $\sim 0.45$ for HEA and ANL; $\sim 0.55$ for TBA; and $\sim 0.60$ for BLA. These values compare with the values of 0.50 and 0.60 in binary mixtures of 2-methoxyethanol with DEA and TEA, respectively, reported by Kinart et al. [39]. The negative excess molar volumes, $V^{E}$, are attributable mainly to the association between the named amines and 2-methoxyethanol through intermolecular hydrogen bonds between the $-\mathrm{OH}$ groups in 2 -methoxyethanol and the nitrogen atoms in the amines. The magnitudes of the negative excess molar volumes were in the order TBA > TEA > DEA > HEA for the binary mixtures with the aliphatic amines while the magnitudes were in the order BLA > ANL for the binary mixtures with the aromatic amines. The strength of the associations arising from the interactions between the unlike molecules was stronger than the strength of the associations between like molecules. Large negative excess molar volumes, $V^{E}$, for binary mixtures of alkyl amines and alcohols have also been reported by other 
TABLE 5: Fitting coefficients and standard deviations of binary mixtures of 2-EtO-EtOH and amines at 298.15 K.

\begin{tabular}{lccccc}
\hline Binary mixtures $\left(V^{E} / \mathrm{cm}^{3} \mathrm{~mol}^{-1}\right)$ & $A_{0}$ & $A_{1}$ & $A_{2}$ & $A_{3}$ & $A_{4}$ \\
\hline Hexylamine $\left(V^{E} / \mathrm{cm}^{3} \mathrm{~mol}^{-1}\right)$ & 0.0004 & -1.1388 & 1.4450 & -0.0057 & -0.3010 \\
Diethylamine $\left(V^{E} / \mathrm{cm}^{3} \mathrm{~mol}^{-1}\right)$ & 0.0138 & -8.0392 & 5.0065 & 9.3689 & -6.3484 \\
Triethylamine $\left(V^{E} / \mathrm{cm}^{3} \mathrm{~mol}^{-1}\right)$ & -0.0093 & -8.6660 & 10.9674 & -2.3938 & 0.0014 \\
tert-Butylamine $\left(V^{E} / \mathrm{cm}^{3} \mathrm{~mol}^{-1}\right)$ & 0.0013 & -6.2890 & 2.6172 & 5.7050 & -2.0278 \\
Aniline $\left(V^{E} / \mathrm{cm}^{3} \mathrm{~mol}^{-1}\right)$ & 0.0005 & -1.1728 & 0.0696 & 1.3485 & -0.2423 \\
Benzylamine $\left(V^{E} / \mathrm{cm}^{3} \mathrm{~mol}^{-1}\right)$ & -0.0018 & -2.2060 & 1.9367 & 0.2404 & 0.0196 \\
\hline
\end{tabular}

workers [40]. It has been suggested that the large negative values are due to heteroassociation of unlike molecules which give rise to formation of cross complexes where $\mathrm{O}-\mathrm{H}-\mathrm{N}$ bonds of the mixtures are stronger than $\mathrm{O}-\mathrm{H}-\mathrm{O}$ and $\mathrm{N}-\mathrm{H}-\mathrm{N}$ bonds of the single component solvents. It is generally known that alkyl groups are electron donating. This ability increases with chain length and branching. This suggests that the nitrogen atom in the amines is electron enriched to different degrees depending upon the chain length and degree of branching of the alkyl groups attached to the nitrogen atom in the amines. The degree of electron enrichment of the nitrogen atom in the amines therefore affects the $\mathrm{N}-\mathrm{H}$ dipole in the amines. The strength of the $\mathrm{O}-\mathrm{H}-\mathrm{N}$ bonds in the mixtures is thus dependent upon the degree of electron enrichment of the nitrogen atom of the amines. The magnitudes of excess molar volumes of binary mixtures of 2-methoxyethanol and the two aromatic amines are least compared to those of the mixtures with aliphatic amines. Aromatic rings attract electrons and are weakly basic. The interactions of aniline and benzylamine with 2-methoxyethanol thus result in small negative $V^{E}$ values. Since the direct attachment of $-\mathrm{NH}_{2}$ group to a carbon atom of an aromatic ring reduces the basic strength of the $\mathrm{NH}_{2}$ group, the magnitudes of $V^{E}$ values for the mixtures of ANL with 2-methoxyethanol are smaller than those of BLA mixtures. Another effect that could account for the negative excess molar volumes of binary mixtures of 2-methoxyethanol and the named amines is the difference in the molecular volumes between 2methoxyethanol and the named amines. 2-Methoxyethanol has molecular volume of $1.31 \times 10^{-22} \mathrm{~cm}^{3}$. The molecular volumes of aniline, benzylamine, hexylamine, diethylamine, triethylamine, and tert-butylamine are $1.35 \times 10^{-22} \mathrm{~cm}^{3}, 1.79 \times$ $10^{-22} \mathrm{~cm}^{3}, 2.20 \times 10^{-22} \mathrm{~cm}^{3}, 1.74 \times 10^{-22} \mathrm{~cm}^{3}, 2.33 \times 10^{-22} \mathrm{~cm}^{3}$, and $1.76 \times 10^{-22} \mathrm{~cm}^{3}$, respectively. The molecular volume of $2-\mathrm{MeO}-\mathrm{EtOH}$ is smaller than the molecular volume of all the amines. This situation can therefore result in the fitting of smaller 2-MeO-EtOH molecules into the amines and result in the negative excess volumes. The molecular volume of TEA is much greater than that of DEA. More molecules of 2-MeO-EtOH can therefore fit into TEA than into DEA. The more negative excess molar volumes in binary mixtures of 2-MeO-EtOH + TEA than in binary mixtures of $2-\mathrm{MeO}-\mathrm{EtOH}+\mathrm{DEA}$ are therefore in line with the molecular volume differences between TEA and DEA. Our results in this regard are at variance with those of Kinart et al. [39], who reported that the excess molar volumes of binary mixtures of 2-methoxyethanol + DEA were more negative than those in binary mixtures of 2-methoxyethanol + TEA. The excess molar volumes, $V^{E}$, of binary mixtures of 2ethoxyethanol and the named amines at $298.15 \mathrm{~K}$ were also negative over the entire range of solvents composition. Plots of the excess molar volumes as a function of mole fraction of 2-ethoxyethanol show minima in the mole fraction range of $0.40 \sim 0.55$. The minima for DEA and TEA occur at the mole fractions of 0.45 and 0.50 , respectively, in these solvent systems. The excess molar volumes of the binary mixtures of 2-ethoxyethanol and the named aliphatic amines were less negative than those in the binary mixtures of 2 methoxyethanol and the named aliphatic amines. The excess molar volumes of binary mixtures of 2-ethoxyethanol and the named aromatic amines were more negative than the values in mixtures of 2-methoxyethanol and the named aromatic amines. As stated earlier, alkoxyethanols are associated via inter- and intramolecular hydrogen bonding. The values of the excess molar volumes, $V^{E}$, are reported to become more negative when the alkyl chain length of the alkoxyethanol increases [41]. Our results however suggest that other factors, such as the differences in the molecular sizes of the component molecules, also play a role in the mixing behavior of the component solvents. The magnitudes of the excess molar volumes of binary mixtures of 2-ethoxyethanol and the named aliphatic amines are in the order DEA $>$ TEA $>\mathrm{TBA}>\mathrm{HEA}$ in the mole fraction range $\leq 0.502$-EtOEtOH. At mole fractions of 2-EtO-EtOH $>0.50$, the order of magnitudes is TBA $>$ TEA $>$ DEA $>$ HEA. This trend suggests that steric hindrance dominates over specific interactions at lower concentrations of 2-EtO-EtOH. DEA, being the least bulky branched amine, therefore has strongest interaction with 2-EtO-EtOH. Interstitial fittings of smaller molecules into molecules with larger molecular volumes have also been reported in binary mixtures of ethylacetoacetate and $\left(\mathrm{C}_{4}-\mathrm{C}_{6}\right)$ aliphatic ketones by Izonfuo and Kemeakegha [42], for binary mixtures of $n$-methylpyrrolidone with $\left(\mathrm{C}_{1}-\mathrm{C}_{10}\right)$ alkan-1-ols [43], formamide and ethanol mixtures [44, 45], and dimethylsulfoxide and alcohols [46-48]. In the binary mixed solvents with compositions above 0.50 mole fraction of 2-ethoxyethanol, intermolecular hydrogen bonding between unlike molecules predominates and the trend is similar to that in the binary mixtures of 2-methoxyethanol with the named amines. The order of magnitude of the negative excess molar volumes of mixtures of 2-EtO-EtOH + the aromatic amines follows the same trend as those in $2-\mathrm{MeO}-\mathrm{EtOH}+$ amine mixtures. In general, the magnitudes of the negative excess molar volumes of mixtures of $2-\mathrm{MeO}-\mathrm{EtOH}$ with the amines 
are larger than those of 2-EtO-EtOH mixtures. The increased chain length of the ethyl group in 2-EtO-EtOH may have created additional steric hindrance in 2-EtO-EtOH mixtures resulting in relative volume expansion compared to that of the methyl group in 2-methoxyethanol.

\section{Conclusions}

Volumetric properties of binary mixtures of 2-methoxyethanol and 2-ethoxyethanol with hexylamine, diethylamine, triethylamine, tert-butylamine, aniline, and benzylamine have been studied at $298.15 \mathrm{~K}$. The results confirm what has been previously reported that, in the solvent systems investigated, the excess molar volumes are negative throughout the entire range of solvents composition. The negative excess molar volumes are attributable to stronger hydrogen bond formations between unlike molecules than those between like molecules. Interstitial fitting of molecules of smaller molecular volumes into molecules of larger molecular volume also account for the negative excess molar volumes of the solvent systems. The relative magnitudes of the negative excess volumes suggest that the excess molar volumes tend to become less negative as the chain length of the alkoxy group increases, which may be due to increased steric hindrance.

\section{Conflict of Interests}

The authors declare that there is no conflict of interests regarding the publication of this paper.

\section{References}

[1] A. K. Nain, "Densities and volumetric properties of binary mixtures of formamide with 1-butanol, 2-butanol, 1,3butanediol and 1,4-butanediol at temperatures between 293.15 and 318.15 K," Journal of Solution Chemistry, vol. 36, no. 4, pp. 497-516, 2007.

[2] A. Pal and A. Kumar, "Excess molar volumes and viscosities for binary mixtures of alkoxypropanols with 1-alkanols at 298.15 K," Journal of Molecular Liquids, vol. 123, no. 2-3, pp. 146-151, 2006.

[3] M. V. Rathnam, S. Mohite, and M. S. S. Kumar, "Density, excess volume, and viscosity of vinyl acetate or benzyl acetate with (o-, $m$-, $p$-)xylenes and ethylbenzene at $T=(303.15$ and 313.15$) \mathrm{K}$, Journal of Solution Chemistry, vol. 39, no. 11, pp. 1735-1748, 2010.

[4] V. A. Rana, H. Chaube, and D. H. Gadani, "Dielectric permittivity, density, viscosity and refractive index of binary mixtures of anisole with methanol and 1-propanol at different temperatures," Journal of Molecular Liquids, vol. 164, no. 3, pp. 191-196, 2011.

[5] S. Nallani and V. Jaana, "Thermodynamic and transport properties of binary liquid mixtures of n-methylacetamide with alkyl (methyl, ethyl, n-propyl and n-butyl) acetates at $308.15 \mathrm{~K}$," Rasayan Journal of Chemistry, vol. 1, no. 3, pp. 602-608, 2008.

[6] A. Pal, H. Kumar, R. Maan, and H. K. Sharma, "Volumetric and acoustic studies of binary liquid mixtures of dipropylene glycol dimethyl ether with methyl acetate, ethyl acetate and $n$-butyl acetate in the temperature range $T=(288.15,293.15,298.15$, 303.15, and 308.15) K,' Journal of Solution Chemistry, vol. 42, no. 10, pp. 1988-2011, 2013.
[7] L. C. Ribeiro, M. D. S. Santos, and A. P. Paiva, "Apparent molar volumes of $N, N$-disubstituted monoamides: a convenient tool to interpret iron(Iii) extraction profiles from hydrochloric acid solutions," Solvent Extraction and Ion Exchange, vol. 31, pp. 281296, 2013.

[8] M. S. AlTuwaim, K. H. A. E. Alkhaldi, A. S. Al-Jimaz, and A. A. Mohammad, "Comparative study of physico-chemical properties of binary mixtures of $N, N$-dimethylformamide with 1-alkanols at different temperatures," The Journal of Chemical Thermodynamics, vol. 48, pp. 39-47, 2012.

[9] A. A. Mohammad, M. S. AlTuwaim, K. H. A. E. Alkhaldi, and A. S. Al-Jimaz, "Viscosity and surface tension of binary systems of $N, N$-dimethylformamide with alkan-1-ols at different temperatures," The Journal of Chemical Thermodynamics, vol. 56, pp. 106-113, 2013.

[10] M. S. AlTuwaim, K. H. A. E. Alkhaldi, A. S. Al-Jimaz, and A. A. Mohammad, "Physico-chemical properties of binary mixtures of N,N-dimethylformamide with 1-octanol, 1-nonanol and 1decanol at different temperatures," The Journal of Chemical Thermodynamics, vol. 58, pp. 367-376, 2013.

[11] L. Venkatramana, K. Sreenivasulu, K. Sivakumar, and K. Dayananda Reddy, "Thermodynamic properties of binary mixtures containing 1-alkanols," Journal of Thermal Analysis and Calorimetry, vol. 115, no. 2, pp. 1829-1834, 2014.

[12] M. Habibullah, I. M. M. Rahman, M. A. Uddin et al., "Densities, viscosities, and speeds of sound of binary mixtures of heptan1-ol with 1,4-dioxane at temperatures from (298.15 to 323.15) $\mathrm{K}$ and atmospheric pressure," Journal of Chemical and Engineering Data, vol. 58, no. 11, pp. 2887-2897, 2013.

[13] F. E. M. Alaoui, E. A. Montero, G. Qiu, F. Aguilar, and J. $\mathrm{Wu}$, "Liquid density of biofuel mixtures: 1-heptanol + heptane system at pressures up to $140 \mathrm{MPa}$ and temperatures from 298.15 K to 393.15 K," The Journal of Chemical Thermodynamics, vol. 65, pp. 174-183, 2013.

[14] A. Ali, A. K. Nain, B. Lal, and D. Chand, "Densities, viscosities, and refractive indices of binary mixtures of benzene with isomeric butanols at $30^{\circ} \mathrm{C}$, International Journal of Thermophysics, vol. 25, no. 6, pp. 1835-1847, 2004.

[15] A. Pal and A. Kumar, "Excess molar volumes and viscosities of binary liquid mixtures of $n$-alkoxyethanol + 1-propanol systems at 298.15, 308.15 and $318.15 \mathrm{~K}$, ' Indian Journal of Chemistry A, vol. 43, pp. 722-729, 2004.

[16] A. Pal and A. Kumar, "Excess molar volumes and viscosities of binary mixtures of some polyethers with 1-propanol at 288.15, $298 \cdot 15$, and 308.15 K," Journal of Chemical Sciences, vol. 116, no. 1, pp. 39-47, 2004.

[17] B. Sinha, "Excess molar volumes, viscosity deviations and speeds of sound for some alkoxyethanols and amines in cyclohexanone at $298.15 \mathrm{~K}$, ' Physics and Chemistry of Liquids, vol. 48, no. 2, pp. 183-198, 2010.

[18] L. Sarkar and M. N. Roy, "Investigation on viscous synergism and antagonism prevailing in binary mixtures of cyclohexylamine with isomeric butanols by volumetric, viscometric, refractive index and ultrasonic speed measurements," Physics and Chemistry of Liquids, vol. 49, no. 2, pp. 219-236, 2011.

[19] J. A. González, "Thermodynamics of mixtures containing amines. X. Systems with cyclic amines or morpholine," Industrial \& Engineering Chemistry Research, vol. 50, no. 16, pp. 98109820, 2011.

[20] M. N. Roy, R. K. Das, and R. Chanda, "Study on solution properties of binary mixtures of some industrially important solvents with cyclohexylamine and cyclohexanone at $298.15 \mathrm{~K}$," 
International Journal of Thermophysics, vol. 31, no. 3, pp. 535545, 2010.

[21] A. Pal, R. Gaba, and S. Sharma, "Densities, excess molar volumes, speeds of sound, and isothermal compressibilities for 2-(2-hexyloxyethoxy)ethanol $+n$-alkylamine at temperatures between $288.15 \mathrm{~K}$ and $308.15 \mathrm{~K}$," Journal of Chemical \& Engineering Data, vol. 53, no. 7, pp. 1643-1648, 2008.

[22] S. R. Patil, U. G. Deshpande, and A. R. Hiray, "Molecular interaction studies of binary liquid mixtures of 1-hexanol and 1-heptanol with nitrobenzene as a common solvent," Rasayan Journal of Chemistry, vol. 3, no. 1, pp. 66-73, 2010.

[23] P. P. Patil, S. R. Patil, A. U. Borse, and D. G. Hundiwale, "Density, excess molar volume and apparent molar volume of binary liquid mixtures," Rasayan Journal of Chemistry, vol. 4, no. 3, pp. 599-604, 2011.

[24] S. L. Oswal and H. S. Desai, "Studies of viscosity and excess molar volume of binary mixtures: 4. 1-Alkanol + trin-butylamine mixtures at 303.15 and 313.15 K," Fluid Phase Equilibria, vol. 204, no. 2, pp. 281-294, 2003.

[25] S. L. Oswal, "Studies of viscosity and excess molar volume of binary mixtures: 5 . Characterization of excess molar volume of 1-alkanol with alkylamines, dialkylamines and trialkylamines in terms of the ERAS model," Thermochimica Acta, vol. 425, no. 12, pp. 59-68, 2005.

[26] S. L. Oswala and S. P. Ijardar, "Studies of partial molar volumes of alkylamine in non-electrolyte solvents III: alkyl amines in butanols at 303.15 K," Journal of Molecular Liquids, vol. 144, no. 3, pp. 115-123, 2009.

[27] G. P. Dubey and K. Kumar, "Studies of thermophysical properties of binary liquid mixtures of amine and alcohols at various temperatures," The Journal of Chemical Thermodynamics, vol. 50, pp. 7-14, 2012.

[28] G. P. Dubey and K. Kumar, "Studies of thermodynamic, thermophysical and partial molar properties of liquid mixtures of diethylenetriamine with alcohols at 293.15 to 313.15 K," Journal of Molecular Liquids, vol. 180, pp. 164-171, 2013.

[29] S. S. Ahmad, M. Yaqub, and A. Karim, "Studies on three excess properties of binary liquid mixtures of 1-butylamine with some alcohols at two different temperatures," Journal of Natural Sciences and Mathematics, vol. 46, pp. 21-32, 2006.

[30] C. M. Saxena, A. Saxena, A. K. Srivastava, and N. K. Shukla, "Densities, viscosities and ultrasonic studies of binary liquid mixture of ethylamine and benzyl alcohol at different temperatures," American Chemical Science Journal, vol. 3, no. 4, pp. 468478, 2013.

[31] M. Kwaterski, E. N. Rezanova, and R. N. Lichtenthaler, "Excess molar volumes and excess molar enthalpies of binary and ternary mixtures of 1-butanol, a tertiary amine (tri- $n$ butylamine or tri- $n$-octylamine) and $n$-hexane: experimental results and ERAS-model calculations," The Journal of Chemical Thermodynamics, vol. 38, no. 10, pp. 1199-1213, 2006.

[32] A. Pal and H. Kumar, "Excess molar volumes and partial molar volumes of dipropylene glycol monomethyl ether + n-alkanol mixtures at $25^{\circ}$ C", Journal of Solution Chemistry, vol. 30, no. 5, pp. 411-423, 2001.

[33] A. Pal and A. Kumar, "Temperature dependence of the volumetric properties of some alkoxypropanols $+n$-alkanol mixtures," The Journal of Chemical Thermodynamics, vol. 36, no. 3, pp. 173182,2004

[34] A. Pal and A. Kumar, "Excess molar volumes and viscosities for binary mixtures of dipropylene glycol monomethyl ether and of dipropylene glycol monobutyl ether with 1-propanol and 2propanol at 298.15 K," Journal of the Indian Chemical Society, vol. 80, pp. 824-831, 2003.

[35] M. D. Holgado, C. Deschaefer, and E. L. Arancibia, "Viscosities, densities, and excess volumes at various temperatures for 2methoxyethanol (1) + 2-butanone (2)," Journal of Chemical and Engineering Data, vol. 41, no. 6, pp. 1429-1430, 1996.

[36] J. Riddick and W. B. Bunger, Organic Solvents, Physical Properties and Methods of Purification, John Wiley \& Sons, New York, NY, USA, 3rd edition, 1970.

[37] J. A. Bunger, W. B. Riddick, and T. K. Sakano, Techniques of Chemistry, Organic Solvents, Physical Properties and Methods of Purification, II, John Wiley \& Sons, New York, NY, USA, 4th edition, 1986.

[38] R. D. Robert, Physical Properties of Chemical Compounds, American Chemical Society, 1981.

[39] C. M. Kinart, W. J. Kinart, D. Checinska-Majak, and A. Bald, "Densities and relative permittivities for mixtures of 2methoxyethanol with DEA and TEA, at various temperatures," Journal of Thermal Analysis and Calorimetry, vol. 75, no. 1, pp. 347-354, 2004.

[40] I. R. Radović, M. J. Kijevčaninand, and A. Ž. Tasić, "Densities and excess molar volumes of alcohol + cyclohexylamine mixtures," The Journal of the Serbian Chemical Society, vol. 74, no. 11, pp. 1303-1318, 2009.

[41] C. M. Kinart, W. J. Kinart, A. Ćwilińska, and M. Klimczak, "Excess molar volumes of the binary mixtures of polyethylene glycol 300 with ethoxyethanols at various temperatures," The Journal of Chemical Thermodynamics, vol. 38, no. 8, pp. 10171024, 2006.

[42] W.-A. L. Izonfuo and J. A. Kemeakegha, "Intermolecular interaction studies of binary mixtures of a ketoester and carbonyl compounds. I: excess volumes of binary mixtures of ethyl acetoacetate with aliphatic ketones at $298.15 \mathrm{~K}$, , Indian Journal of Chemistry A, vol. 48, no. 9, pp. 1242-1246, 2009.

[43] B. García, R. Alcalde, S. Aparicio, J. M. Leal, and J. L. Trenzado, "Thermophysical behavior and temperature effect on the $\mathrm{N}$ methylpyrrolidone $+\left(\mathrm{C}_{1}-\mathrm{C}_{10}\right)$ alkan-1-ols mixed solvents," Industrial \& Engineering Chemistry Research, vol. 42, no. 4, pp. 920-928, 2003.

[44] A. K. Nain, "Ultrasonic and viscometric studies of molecular interactions in binary mixtures of formamide with ethanol, 1propanol, 1,2-ethanediol and 1,2-propanediol at different temperatures," Journal of Molecular Liquids, vol. 140, no. 1-3, pp. 108-116, 2008.

[45] A. Awasthi and A. Awasthi, "Intermolecular interactions in formamide + 2-alkoxyethanols: viscometric study," Thermochimica Acta, vol. 537, pp. 57-64, 2012.

[46] P. K. Pandey and A. Awasthi, "Acoustic, volumetric and spectroscopic investigations in binary mixtures of formamide/Nmethylformamide + 2-chloroethanol at various temperatures," Journal of Molecular Liquids, vol. 187, pp. 343-349, 2013.

[47] F. Comelli, R. Francesconi, A. Bigi, and K. Rubini, "Excess molar enthalpies, molar heat capacities, densities, viscosities, and refractive indices of dimethyl sulfoxide +1 -propanol at (288.15, 298.15, and 308.15) K and at normal pressure," Journal of Chemical \& Engineering Data, vol. 51, no. 5, pp. 1711-1716, 2006.

[48] K. F. Loughlin, "Comments on 'Excess molar enthalpies, molar heat capacities, densities, viscosities, and refractive indices of dimethyl sulfoxide + 1-propanol at $(288.15,298.15$, and 308.15) $\mathrm{K}$ at normal pressures', Journal of Chemical \& Engineering Data, vol. 52, no. 3, p. 1149, 2007. 

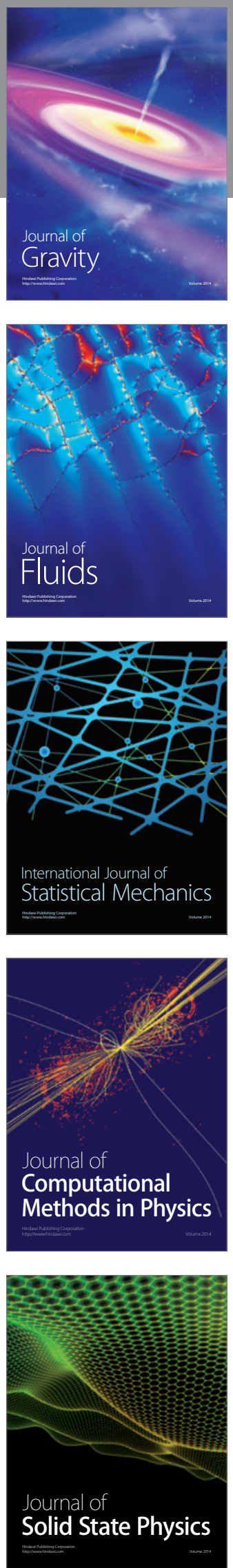

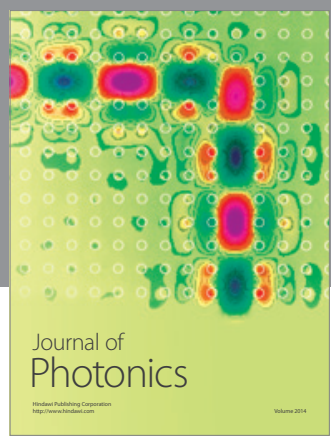

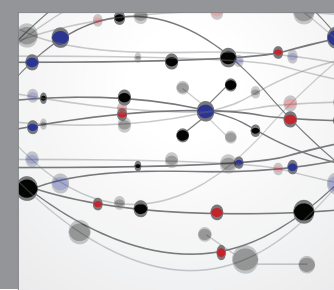

The Scientific World Journal

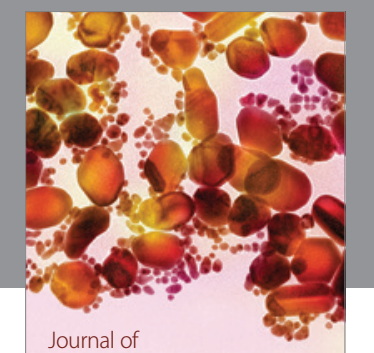

Soft Matter
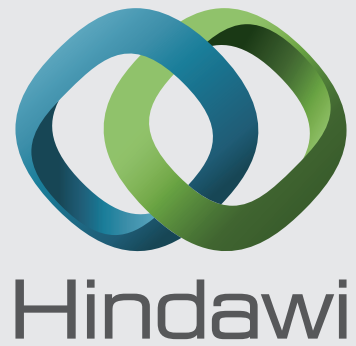

Submit your manuscripts at

http://www.hindawi.com
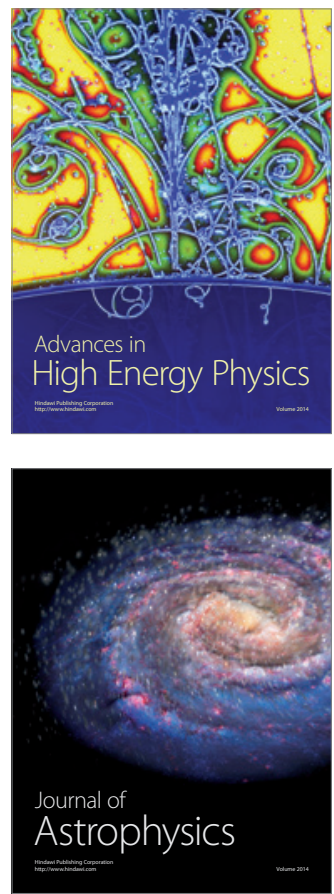
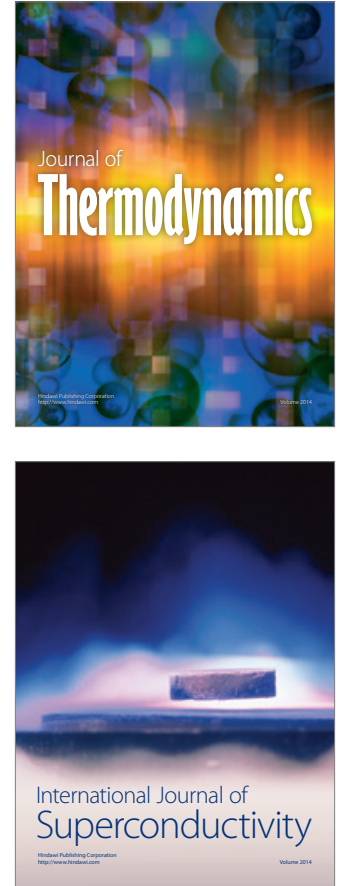
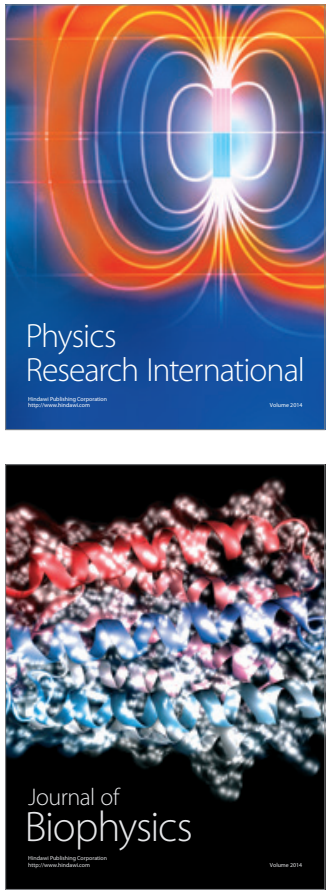
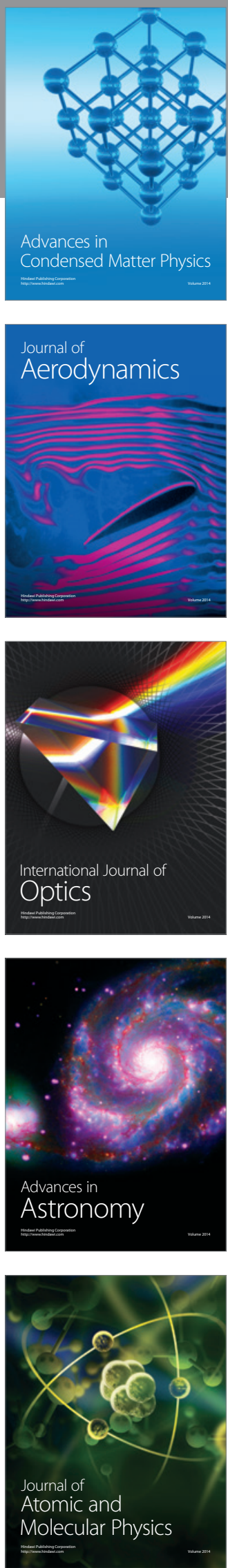